Research Article

\title{
Temperature and Stress Evaluation during Three Different Phases of Friction Stir Welding of AA 7075-T651 Alloy
}

\author{
Kareem N. Salloomi iD, Furat I. Hussein, and Sanaa N. M. Al-Sumaidae \\ University of Baghdad, Al-Khwarizmi College of Engineering, Baghdad, Iraq \\ Correspondence should be addressed to Kareem N. Salloomi; kareem@kecbu.uobaghdad.edu.iq
}

Received 19 November 2019; Revised 14 January 2020; Accepted 22 January 2020; Published 18 February 2020

Academic Editor: Dimitrios E. Manolakos

Copyright ( $\odot 2020$ Kareem N. Salloomi et al. This is an open access article distributed under the Creative Commons Attribution License, which permits unrestricted use, distribution, and reproduction in any medium, provided the original work is properly cited.

\begin{abstract}
The current study performs an explicit nonlinear finite element simulation to predict temperature distribution and consequent stresses during the friction stir welding (FSW) of AA 7075-T651 alloy. The ABAQUS ${ }^{\circledR}$ finite element software was used to model and analyze the process steps that involve plunging, dwelling, and traverse stages. Techniques such as Arbitrary Lagrangian-Eulerian (ALE) formulation, adaptive meshing, and computational feature of mass scaling were utilized to simulate sequence events during the friction stir welding process. The contact between the welding tool and workpiece was modelled through applying Coulomb's friction model with a nonlinear friction coefficient value. Also, the model considered the effect of nonlinear material properties as well as heat transfer conditions such as heat losses due to convection and thermal contact conductance between the workpiece and the backing plate interface on the thermal history. To validate the computational model results, an experimental procedure was carried out to measure temperature history on both sides of the specimen as well as the plunging force throughout the whole process time. The results obtained showed that symmetrical temperature distribution throughout the workpiece width was distinguished, implying that the tool rotation has a minor effect on the final temperature distribution. In addition, asymptotic $\mathrm{V}$ shape with high gradient temperature value in the weld nugget region after the full plunging was distinguished. Mechanical stresses and related plastic deformations generated, while achieving the FSW samples were evaluated in addition to the tool reaction force and heat generated to protect against tool failure.
\end{abstract}

\section{Introduction}

AA 7075 alloy is a heat treatable aluminum alloy that possesses prominent mechanical properties such as functional corrosion protection, maintaining of high strength properties, flexible machinability, and lightweight functions. The high strength properties are usually achieved through the precipitation of $\mathrm{Mg}_{2} \mathrm{Zn}$ and $\mathrm{Al}_{2} \mathrm{CuMg}$ phases. On that basis, this type of $7 \mathrm{xxx}$ aluminum series has been used widely in many aerospace and automotive applications, where components should have specific properties to fulfill the desired mechanical needs as well as being easy to be welded. Although the aluminum high strength alloys have many desirable mechanical properties, welding of high strength alloys like AA 7075 alloy may pose remarkable challenges. It is well known that welding of AA 7075 alloy using conventional methods is usually not easy to be accomplished without serious problems due to weld solidification cracking. Later with the invention of friction stir welding (FSW) process, most of the classical welding problems were resolved. Mishra and Komarasamy [1] categorized the FSW process as the most significant achievement in the joining of materials in the last three decades since it keeps up to $90 \%$ of the mechanical properties of aluminum alloys. For this reason and other versatile advantages, the FSW process attracted considerable attention by researchers, especially for welding high strength alloys like AA 7075. The FSW process has been used with aluminum as well as magnesium and steel-based alloys for improving mechanical properties and inducing superplasticity through grain refinement. In particular, AA 7075 alloy has been used vastly as a structural component in many industrial applications, and, for that 
reason, many authors had carried out experimental investigations on friction stir welding of AA 7075 alloy to find out the optimal process parameters for a sound weld. Zhang et al. [2] probed the mechanical behaviour and microstructural map of high-speed FSWed AA 7075-T6 plates. Different inspection tests were used to distinguish between HAZ, TMAZ, and stir zones. The study showed that using high welding speeds of up to $3 \mathrm{M} / \mathrm{min}$ may return weld with narrower and stronger heat effective zone (HAZ). However, the study of the thermal environment accompanying the FSW process may reveal more information about the microstructural formation, which in turn will assist the researchers in developing a more realistic image concerning the final microstructure and boundaries of welding zones. Chegeni and Kapranos [3] applied a simultaneous doublesided friction stir welding technique to join AA 7075 alloy plates. Postwelding heat treatment was carried out in the semisolid region at a temperature of $628^{\circ} \mathrm{C}$ to check if the weld zone microstructure is formed in a similar way to those encountered in semisolid metal processing. The study demonstrated that the grain size was highly decreased in the nugget zone due to excessive plastic deformation that the material undergoes during FSW which in turn will improve the mechanical strength of the weld zone. However, the study did not explain important quantities that affect plastic deformation such as plastic strain and dissipation energies during FSW process. To follow up, Shah and Badheka [4] conducted an experimental study to capture the temperature history during different phases of AA 7075-T651 FSW process and investigate its effect on the final microstructure. Although the study measured the transient temperature variation around the rim of the tool shoulder, it was challenging to have some information about the temperature variation beneath the shoulder area or along the weld line. Here, it should be pointed out that most of the accomplished experimental literature within the area of FSW of high strength aluminum alloys was carried out using tool speed rotation of 1200-1500 rpm to produce high joint quality without fabrication defects as outlined in Zhang et al. [2], Chegeni and Kapranos [3], and Abbass et al. [5]. As a joining process, the FSW was not free of defects; the improper selection of input welding parameters showed that the friction stir welded specimen had suffered from tunnel defects in the root of the weld line due to both inadequate plunge depth and inappropriate stirring of the material around the tool. In addition, other types of defects were noticed such as microvoids and large grain bands in which these types of defects were formed on the retreating side of the weld line at high speed causing insufficient filling in the joints. To control the probability of having process defects, it is urgent to get more precise data regarding the temperature distribution in the welding zone and about the treated region since it dominates the microstructural map and precipitate distribution. The embedded thermocouples that used to measure the maximum temperature as well as temperature history during the friction stir welding process were usually located at some remote locations that are away from the nugget zone. This indicates a fact that measuring temperature variations in the nugget zone using the thermocouples can not be achieved accurately. To cope with this problem, the finite element method has been proposed as a second option efficient method to develop the simulation models that can predict temperature history, stresses and associated deformations, and material flow engaged during the FSW process. Due to the intricacy of the FSW process, most of the previous published numerical studies that deal with the friction stir welding simulation used either a Pseudoheat transfer model to simulate heat generated by friction between tool and workpiece or a two-dimensional geometry to simplify the process simulation. Hussein $[6,7]$ calculated analytically the amount of the total heat generated through both shoulder and pin tool's parts. The value of the total heat was applied as a Pseudo-heat transfer model to achieve the analysis of the temperature distribution throughout the whole FSW process. Soundararajan et al. [8] used thermomechanical finite element model with an adaptive boundary condition to determine the temperature evolution at the shared region between the tool shoulder and workpiece during the FSW of AA 6061-T6. Although good convergence between experimental and numerical temperature measurement was obtained, no real plunging was demonstrated throughout the study since the tool pin existence was ignored and heat generation due to the interaction between the tool pin and workpiece was not considered in the simulation process. Esmaily and Shokuhfar [9] applied thermomechanical simulation with the assistance of Arbitrary Lagrangian-Eulerian (ALE) technique to control excessive deformation during plunging. The model used decoupled simulation in which the thermal history was first captured and then applied as a load to calculate consequent stresses. Salloomi and Al-Sumaidae [10] implemented a 3D finite element simulation to validate the temperature results of Shah and Badheka [4]. Although the finite element results were in good convergence with the experimental results in both plunging and dwell phases, there was some divergence in the traverse and cooling phases. Jain et al. [11] conducted a three-dimensional coupled thermomechanical finite element study to simulate the FSW of AA2024-T4. The simulation procedure involved using Lagrangian incremental technique to predict temperature, forces, and strain distribution. The study came out with some important conclusions; for example, temperature distribution and plastic strain play a major role in microstructure and grain size of the resulting welded sample. Riahi and Nazari [12] conducted a finite element simulation to model temperature distribution and resulting residual stresses in friction stir welding of aluminum alloy 6061-T6. The numerical results were in good agreement when compared to previous experimental results. However, the simulation process did not involve full geometry of the welding tool in which the tool pin was ignored. El-Sayed et al. [13] used both experimental and numerical procedures to investigate FSW of AA5083-O. The study ignored real interaction between the tool and workpiece and considered a heat flux model to simulate heat generated by friction between tool and workpiece. In fact, the finite element simulations have been useful in adjusting and 
optimizing the process parameters and tool design. Recently, more advanced techniques like Lagrangian, Eulerian, Arbitrary Lagrangian-Eulerian (ALE), and Coupled Eulerian-Lagrangian (CEL) have been applied with a full description of the environment surrounding the problem to get more precise results for the simulation of FSW process. In the Lagrangian formulation, the geometry is discretized into elements and nodes; this mesh will move and distort with the distorted material, whereas in the Eulerian formulation, the mesh remains stable and the material is capable of flow through the prescribed region. The ALE method is an adaptive meshing technique that handles some limitations of the classical Lagrangian and Eulerian-based finite element simulations. The method has the ability to let the mesh within the finite element model to move autonomously of the implied material. This means that the method can preserve a topologically identical mesh throughout the analysis. Al-Badour et al. [14] implemented a finite element CEL model to simulate void formation during friction stir welding of Al-6061-T6. The ultimate value of plunging force and applied torque was in good agreement with the experimental outcomes; however, the axial, transverse, and crossfeed forces were overestimated by the CEL mode. Hossfeld [15] used CEL approach to simulate the whole FSW process of AA 5182-0. The resolution reached within this study allows noticing the formation of burr and internal voids. Meyghani et al. [16] used nonlinear friction coefficient to model friction between the tool and workpiece during FSW of AA 6061-T6. The temperature distribution was captured and compared to the experiment. Although sound correlation between finite element and experimental maximum temperature was achieved, the model was not extended to account for quantities that affect the FSW process such as dissipation energies that are responsible for the heat generation during the process. To go further in explaining the contact issue between the tool and workpiece, Luo et al. [17] designed a neoteric type of friction stir weld spindle system capable of telescoping in addition to rotation. The study implemented a 3D finite element simulation to study heat transfer between the newly designed spindle system and AA2024-T4 workpiece. It was concluded that the newly developed FSW spindle could be used for welding complicated aluminum structures such as those used in the aerospace field. Nevertheless, the study and most of the finite element studies carried out within the same topic assumed that constant friction coefficient which is not representing the real behaviour since this coefficient is going to be reduced as heat generation during process is increased.

Although many studies were conducted to model the temperature history during the friction stir welding of AA 7075-T651 alloy using three-dimensional geometry with a Pseudo-heat transfer model, but none of these applied ALE approach with time-varying friction coefficient value to simulate both thermal and mechanical actual material behaviours during the plunging, dwelling, and traversing steps of the FSW process. Therefore, the mission of the current paper is to implement an ALE explicit fully coupled thermomechanical analysis using ABAQUS simulator to model the three-dimensional FSW process of AA 7075-T651. The model can return quantities such as temperature, stresses, strains, and tool reaction forces in addition to the heat generated results. Moreover, the current study demonstrates temperature and stress evolution throughout all phases (plunging, dwell, and traverse) of FSW process phase step by step. To verify the simulation output, an experimental procedure is carried out to measure temperature distribution throughout the full time of the FSW process.

\section{Temperature and Force Measurement Procedure}

To implement the experimental measurement of the temperature history during the friction stir welding of AA 7075T651 alloy, two workpiece plates were cut and machined into the advancing and retreating sides with the dimensions of $150 \times 50 \times 4 \mathrm{~mm}$ by a power cutting machine. The contact surfaces of the workpiece plates were polished with abrasive papers to avoid some of the negative influences of the oxidation film during the welding process. The FSW samples were achieved using a tool having a threaded cylindrical pin design with an outside diameter of $6.3 \mathrm{~mm}$. The shoulder was prepared with a diameter of $18 \mathrm{~mm}$ and a concave cone profile as an alternative to the plane surface to enclose the material pushed off the mixing zone when the tool pin is immersed into the workpiece through the plunging and traversing steps. For the current experimental tests, a tool rotation speed of $1200 \mathrm{rev} / \mathrm{min}$ and a traverse welding speed of $2 \mathrm{~mm} / \mathrm{s}$ were applied. The K-type thermocouples were used to measure the temperature time-history of two points positioned at $15 \mathrm{~mm}$ away from the welding main path on both advancing and retreating sides of the welding sample. Each thermocouple was placed in a hole of $1 \mathrm{~mm}$ in diameter and $1 \mathrm{~mm}$ in depth and glued using conductive thermal paste. The overall experimental setup was placed on a multicomponent force dynamometer to measure the plunging force during the FSW process. Figure 1 shows a schematic view of the welded plates and location of thermocouples as well as the position of the force dynamometer. A temperature sensor device of type BTM-4208 with a compact digital (SD) card was applied to track thermal history throughout the whole time of the FSW process.

\section{Governing Equations and Computational Model}

3.1. Governing Equations. As a joining process, friction stir welding (FSW) involves high-speed dynamic interactions between the welding tool and sample that compel the process to be resolved using $\mathrm{FE}$ techniques other than implicit solvers. Despite that, explicit solvers can be used to analyze transient thermomechanical problems as well as modelling the complex contact interaction between the individual parts of the treated geometry. The process is described as a coupled thermomechanical problem and thus an element that possesses both thermal and mechanical degrees of freedom is accordingly applied for meshing objectives. The simulation analysis results such as 

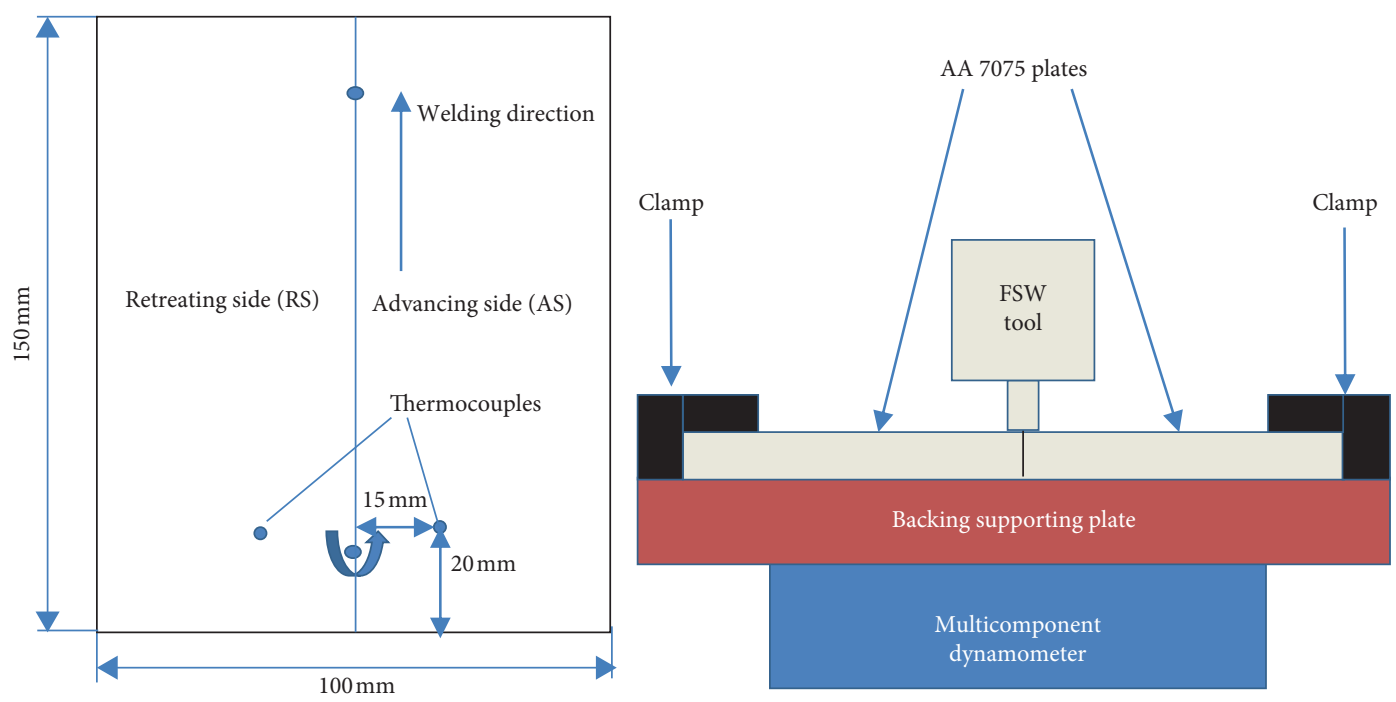

Figure 1: Schematic view of the welded plate and location of thermocouples and force dynamometer.

temperature, stresses, and plastic strains of the AA 7075 material interacting with the welding tool were quantitatively calculated through using ABAQUS/EXPLICIT [18] in conjunction with the ALE adaptive meshing technology in addition to temperature and rate-dependent failure criteria to implement a fully coupled explicit analysis of the AA 7075-T651 FSW process. The governing equation for the transient temperature distribution in the workpiece is like the governing equation of $3 \mathrm{D}$ heat conduction with suitable boundary condition, as described by Spencer [19]:

$$
\nabla\left(K_{k} \nabla T\right)+Q=\rho c \frac{\partial T}{\partial t},
$$

where $K_{k}$ is thermal conductivity in $\mathrm{W} / \mathrm{m} \cdot{ }^{\circ} \mathrm{C}, \rho$ is the density of material $\mathrm{kg} / \mathrm{m}^{3}, C$ is specific heat in $\mathrm{J} / \mathrm{kg} .{ }^{\circ} \mathrm{C}, T$ is temperature in ${ }^{\circ} \mathrm{C}$, and $Q$ is the heat applied during welding. The explicit forward-difference time integration algorithm used by ABAQUS/Explicit is described by Luo et al. [17]. The total heat generation used to achieve the goal of joining through FSW process is composed of two main sources; these are frictional energy dissipation and rate of plastic strain energy dissipation. It is also important to realize that the present study considered a high portion of the plastic work (90\%) and whole frictional work $(100 \%)$ is converted to heat. The rate of plastic strain energy dissipation is figured out through applying, as described by Li et al. [20]:

$$
q^{\text {plastic }}=\eta \sigma \dot{\varepsilon}^{\text {plastic }}
$$

in which $\eta$ is the portion of plastic energy dissipation, $\sigma$ is the deviatoric stress, and $\dot{\varepsilon}^{\text {plastic }}$ is the rate of plastic straining. The rate of frictional energy dissipation is calculated as given by Li et al. [20]:

$$
q^{\text {frictional }}=\tau \dot{\gamma}
$$

Since

$$
\tau=\mu p,
$$

Then, (3) can be rewritten as

$$
q^{\text {frictional }}=\mu p \dot{\gamma}
$$

where $\tau$ is the frictional stress, $\dot{\gamma}$ is the slip rate, $\mu$ is the friction coefficient, and $p$ is the normal contact pressure. The plastic energy dissipation is considered by solving the thermal energy balance governing equation (1). The frictional energy dissipation is put into the model by means of a heat flux boundary condition. Heat loss due to natural convection from the workpiece faces to the ambient was considered and calculated through, as given by Colegrove [21]:

$$
q_{c}=h_{f}\left(T-T_{\infty}\right)
$$

where $h_{f}=$ convection coefficient and $T_{\infty}=$ ambient temperature. The dominant equation that controls the mechanical response of the considered process is the equilibrium equation, as given by $\mathrm{Li}$ et al. [20]:

$$
\rho a=\rho g+\operatorname{div}(\sigma) \text {. }
$$

where $g$ is the body force per unit mass, $\rho$ is the mass density, $\sigma$ is the stress tensor, and $a$ is the acceleration. To solve the above-described equation, ABAQUS/Explicit uses the central difference rule as explained by Luo et al. [17].

3.2. Computational Model. The process and geometrical data of the current model were chosen based on the experimental work explained earlier in Section 2. To reduce the computational time, two small plates of $60 \mathrm{~mm}$ in length, $20 \mathrm{~mm}$ in width, and $4 \mathrm{~mm}$ in thickness were considered instead of the full dimension model. The proposed model consists of a deformable plate which is AA 7075-T651 and an AISI H13 rigid tool as well as a rigid backing supporting plate without any thermal degree of freedom as explained in Figure 2. The geometry design of the main tool used in the finite element model is simplified in a way that does not include the spiral thread because this would result in exaggerated mesh distortion and no solution will be achieved. For meshing 


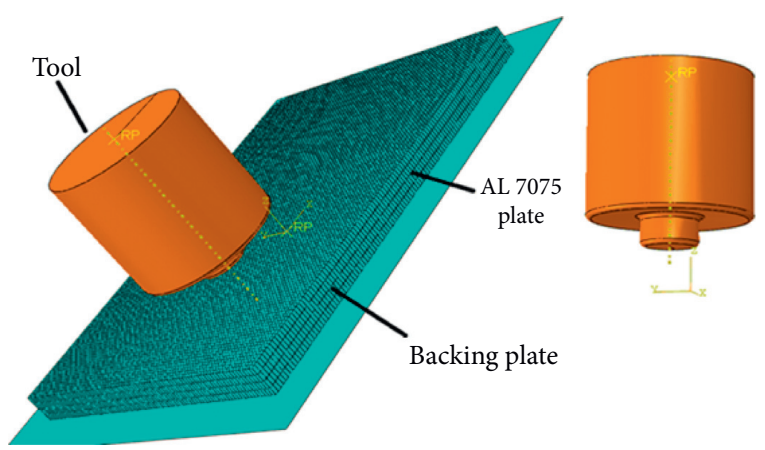

Figure 2: Configuration of the finite element model.

purposes, the eight-node coupled temperature displacement brick element (C3D8RT) was used to discretize the aluminum plate. The element can compute displacement and temperature in $x$-, $y$-, and $z$-directions and produce uniform strain, in addition to using hourglass control feature ABAQUS/EXPLICIT [18]. An element size of $0.5 \mathrm{~mm}$ was used to mesh the plate in both $x$-and $y$-directions, while 4 elements were used in the thickness $z$-direction. A total of 38,400 elements were used to mesh the workpiece while one element of type R3D4 was used to mesh the supporting backing plate.

In the current simulation, the aluminum material was allowed to move autonomously of the finite element discretization; this was fulfilled through considering the whole aluminum plate as an adaptive region. A sliding property region in the main adaptive mesh model was characterized to define the contact between the plate upper surface and tool bottom surface. This consideration enables the mesh to keep track of the material motion in the direction parallel to the plunging direction and at the same time stir was done autonomously of the inherent material in the tangential direction. Similar to the contact between the plate and tool, the same contact algorithm used to model fully coupled thermomechanical problems was applied to define the contact between the bottom surface of the plate and backing supporting plate.

Concerning material behaviour, a temperature and strain rate-dependent material law was applied through adopting the elastoplastic Johnson-Cook model to calculate the flow stress as shown in (8), explained by Jørgensen and Swan [22]:

$$
\sigma=\left(A+B \varepsilon^{n}\right)\left[1+C \ln \left(1+\frac{\dot{\varepsilon}}{\dot{\varepsilon}_{0}}\right)\right]\left[1-\left(\frac{T-T_{\text {room }}}{T_{\text {melt }}-T_{\text {room }}}\right)^{m}\right],
$$

where $\varepsilon$ and $\dot{\varepsilon}$ are the effective plastic strain and strain rates, respectively, $\dot{\varepsilon}_{0}$ is the reference strain rate, $T_{\text {room }}$ is the reference temperature, and $T_{\text {melt }}$ is the melting temperature. $A$, $B, n, C$, and $m$ are material constants. Table 1 shows the model constants for AA 7075-T651, as explained by Jørgensen and Swan [22].

The friction between the welding tool and aluminum workpiece was satisfied through applying Coulomb's friction law with a nonlinear friction value that varies with respect to
TABLE 1: Johnson-Cook strength model constant for AA 7075T651.

\begin{tabular}{lcccccc}
\hline$A(\mathrm{MPa})$ & $B(\mathrm{MPa})$ & $n$ & $C$ & $m$ & $T_{\text {melt }}\left({ }^{\circ} \mathrm{C}\right)$ & $T_{\text {room }}\left({ }^{\circ} \mathrm{C}\right)$ \\
\hline 520 & 420 & 0.52 & 0.001 & 1.61 & 620 & 25 \\
\hline
\end{tabular}

the temperature at that zone. To achieve the sliding situation, the simulation considered an equivalent shear stress condition of $\tau_{\max }$. The condition states that if the equivalent shear stress value attains its maximum value, then the sliding situation will be satisfied regardless of the value of the contact pressure stress. The von Mises theory was used to calculate the maximum limit of the equivalent shear stress through using

$$
\tau_{\max }=\frac{\sigma_{y}}{\sqrt{3}}
$$

in which $\sigma_{y}$ is the Mises yield stress of the material in contact. Due to insufficient data about the friction coefficient of AA 7075-T651 alloy, the friction coefficient values used in [16] for AA 6061 were adopted. The contact between the AA 7075 plate and the backing plate was assumed to be frictionless. To achieve realistic simulation, nonlinear, thermal, and mechanical material properties were considered by Mills [23]. Table 2. illustrates the material properties variation with respect to temperature change for AA 7075 alloy.

Structural boundary conditions were applied to constrain the motion of the AA 7075 plate. To do so, the backing plate that supports the AA 7075 alloy was used also to prevent any motion in any direction; moreover, the AA 7075 plate edges that are parallel to the weld path were also fully fixed so that no rigid body motion is permitted. The temperature surrounding the whole model was set to the environmental temperature of $20^{\circ} \mathrm{C}$ at the beginning of the analysis. Convective boundary conditions were also applied on the upper and sides surfaces of the AA 7075 plate with a convective coefficient of $h_{f}=10 \mathrm{~W} / \mathrm{m}^{2} \cdot{ }^{\circ} \mathrm{C}$. The heat conduction between the bottom surface of the welded plate and backing supporting plate was modelled through assuming a higher value of convective coefficient $\left(h_{f}=1000 \mathrm{~W} / \mathrm{m}^{2} \cdot{ }^{\circ} \mathrm{C}\right)$. The reason behind this assumption is the high complexity in getting precise thermal conductivity value for the gap that exists between AA 7075 plate and backing supporting plate, as described by Salloomi [24].

In the present simulation, both tool rotation speed $(1200 \mathrm{rev} / \mathrm{min})$ and traverse speed $(2 \mathrm{~mm} / \mathrm{s})$ were applied on the tool reference point, while the workpiece plate was constrained at the bottom and sides. The plunge, dwell, and moving times in the simulations were 12.1, 0.2, and $15.2 \mathrm{sec}$, respectively. To avert instability effects caused by the lateral motion of the welding tool at the beginning of the moving step, the traverse welding speed was assigned by a set of values at points in time in ABAQUS, as shown in Figure 3. It is also worthy of mentioning that the Arbitrary Lagrangian-Eulerian (ALE) approach was used in accordance with the adaptive meshing and the mass scaling techniques to minimize the time required to finish FSW simulation. 
TABLE 2: Variation of thermal and mechanical properties of AA 7075.

\begin{tabular}{lcccccc}
\hline $\begin{array}{l}\text { Temperature } \\
\left({ }^{\circ} \mathrm{C}\right)\end{array}$ & $\begin{array}{c}\text { Thermal conductivity } \\
\left(\mathrm{W} / \mathrm{m} \cdot{ }^{\circ} \mathrm{C}\right)\end{array}$ & $\begin{array}{c}\text { Density }(\mathrm{kg} / \\
\left.\mathrm{m}^{3}\right)\end{array}$ & $\begin{array}{c}\text { Young's } \\
\text { modulus }(\mathrm{GPa})\end{array}$ & $\begin{array}{c}\text { Poisson's } \\
\text { ratio }\end{array}$ & $\begin{array}{c}\text { Coefficient of thermal } \\
\text { expansion }\left(1 /{ }^{\circ} \mathrm{C}\right)\end{array}$ & $\begin{array}{c}\text { Specific heat capacity } \\
\left(\mathrm{J} / \mathrm{Kg} \cdot{ }^{\circ} \mathrm{C}\right)\end{array}$ \\
\hline 25 & 130 & 2810 & 71.1 & 0.33 & $2.16 E-005$ & 870 \\
100 & 186 & 2800 & 65.2 & 0.33 & $2.34 E-005$ & 910 \\
200 & 197 & 2770 & 56.3 & 0.33 & $2.36 E-005$ & 960 \\
300 & 194 & 2750 & 38.0 & 0.33 & $2.43 E-005$ & 1050 \\
400 & 196 & 2730 & 31.5 & 0.33 & $2.52 E-005$ & 1100 \\
500 & 196 & 2700 & 25.0 & 0.33 & $2.61 E-005$ & 1110 \\
532 & 193 & 2690 & 24.0 & 0.33 & $2.75 E-005$ & \\
\hline
\end{tabular}

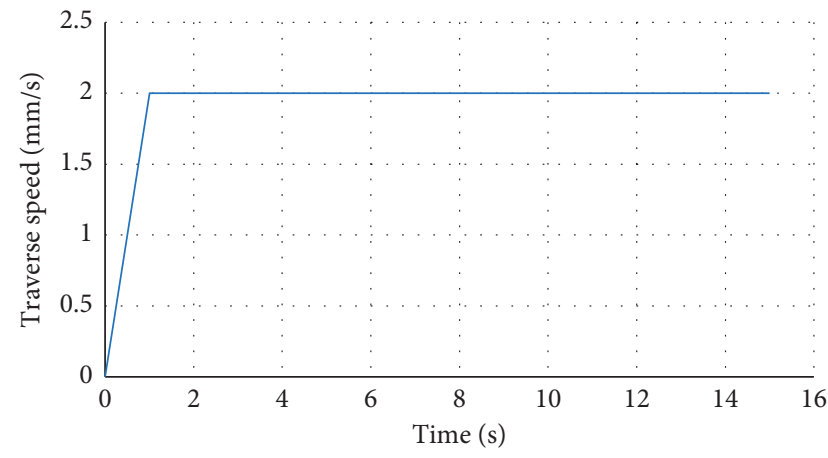

Figure 3: Traverse speed versus time.

\section{Model Results and Discussion}

4.1. Thermal Environment Evolution. The present finite element model has the prospect of evaluating FSW process outcomes like temperature, stresses, plastic strain, plunge force, and heat generation throughout the three unliked steps of friction stir welding of AA 7075-T651 and over the entire region of the welded structure. As we declared above, the ABAQUS/EXPLICIT software was used to simulate heat transfer in plunging, dwelling, and traverse steps of the FSW process. Figure 4 shows temperature distribution at six distinct time points over the 27.5 -second process period. To illustrate temperature distribution throughout thickness direction, Figure 4 also displays the cross section of the welding joint in the upper line while the bottom line provides the top view without a welding tool. The simulation results demonstrate that when the tool pin comes into contact with the AA 7075 plate to start penetration, the temperature has risen to some maximum value in the zone locally beneath the pin bottom surface, and semicircle temperature contours propagate through the plate surface. The temperature keeps growing up at the same site until the shoulder comes in contact with the AA 7075 plate; subsequently, the maximum temperature skips to the corner zone between the pin and shoulder interfacial surfaces. At $12.1 \mathrm{sec}$ the contact between tool and workpiece increased causing the temperature to grow up to its maximum value of $599^{\circ} \mathrm{C}$ around the shoulder-workpiece interface; this is due to the occurrence of complete contact between the workpiece and the tool; in addition, the plunging force and the torque granted to the tool were higher than the other steps, as described by Fraser et al. [25]. Later on, the temperature decreased slightly and tended to be more stable in the dwell and traverse stages. It is also clear to notice a high-temperature variation with a "V" pattern as shown in Figure 4 on the upper surface of the AA 7075 plate; this indicates high-temperature heat flow occurrence in the coherence layer between the tool's shoulder and the workpiece.

Figure 5 illustrates temperature change across plate width at a path located at the starting position of the plunging (section A-A). A dwelling of $0.2 \mathrm{sec}$ was enough to satisfy a case of even temperature distribution between the leading and trailing sides of the tool. Due to the high temperature achieved at the backside of the tool, the formation of the burr behind the tool was remarkably noticed in the plunging and dwelling phases compared to the front side. Later, the tool moves in a traverse direction to join the two plates together. The process showed little variations in temperature profile as illustrated by contour images. Also, the force and torque applied in the traverse stage show little degradation after dwell stage due to material softening as explained in the next sections. As can be seen from Figure 5, the temperature distribution between the advancing side (AS) and the retreating side (RS) was symmetrical when complete contact occurred at times 12.1 and $12.3 \mathrm{sec}$. The symmetrical distribution indicates that the tool rotation direction has no effect on the final temperature history across the welded specimen. This fact agrees well with the previously published results of Reese [26] and Li et al. [20]. Figure 6 shows the correlation between experimentally measured and numerically predicted temperature histories of two points located on advancing and retreating sides of the welded specimen. The numerically estimated temperature does not exactly match the experimentally measured value. The finite element model was found to be overestimated by $8 \%$. The reason behind this divergence can be assigned to the inability of choosing accurate convection coefficient value to model heat waste by conduction through the supporting backing plate, as well as neglecting heat waste from the workpiece into the stirring tool. Further, the figure also shows a slight deviation in the place of the maximum temperature value; this is because the actual experimental plunging speed was slower than the speed applied in the simulation analysis. Here, it is important to emphasize the fact that the maximum temperature during the FSW process did not exceed the melting temperature for AA 7075-T651 which ensures the high potential of the finite element method in achieving accurate results for such analysis. 

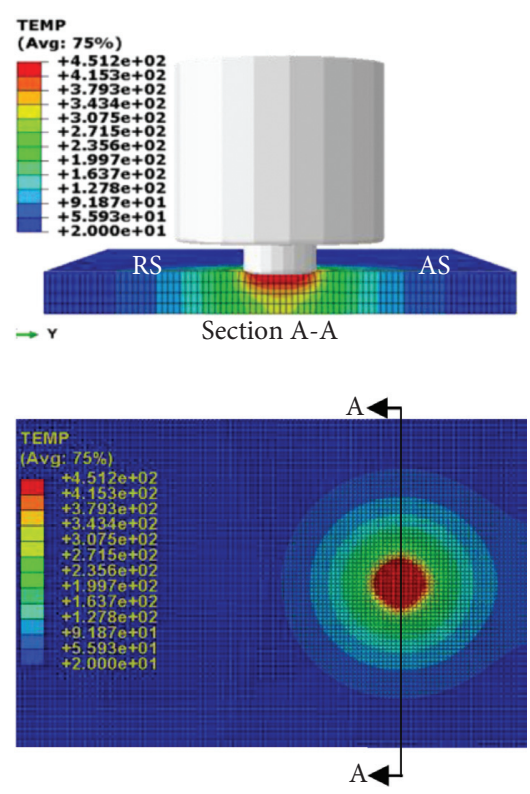

(a)
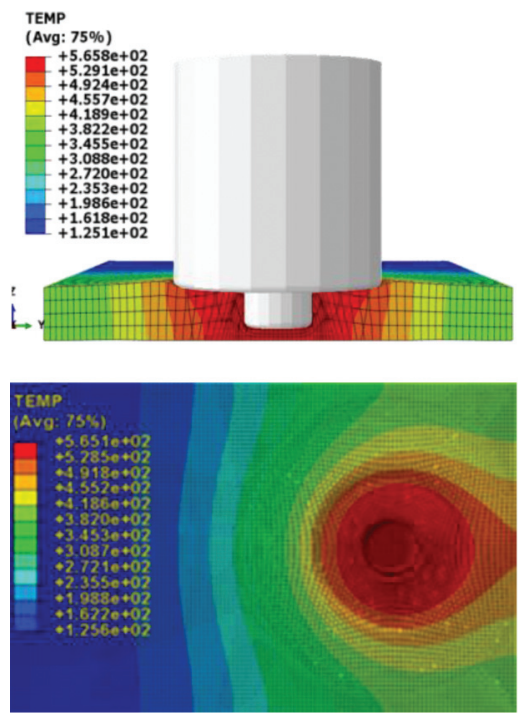

(d)
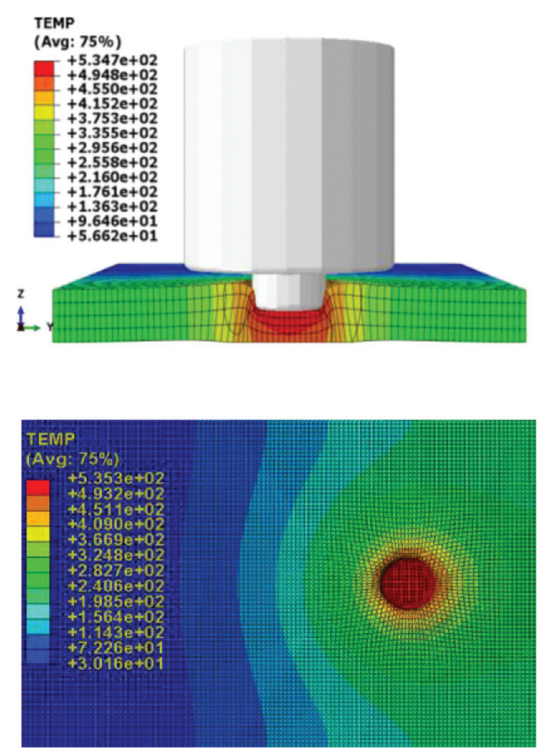

(b)
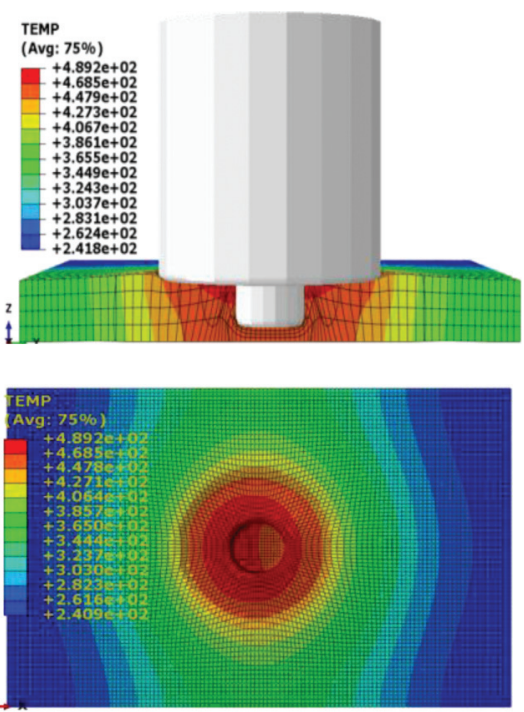

(e)
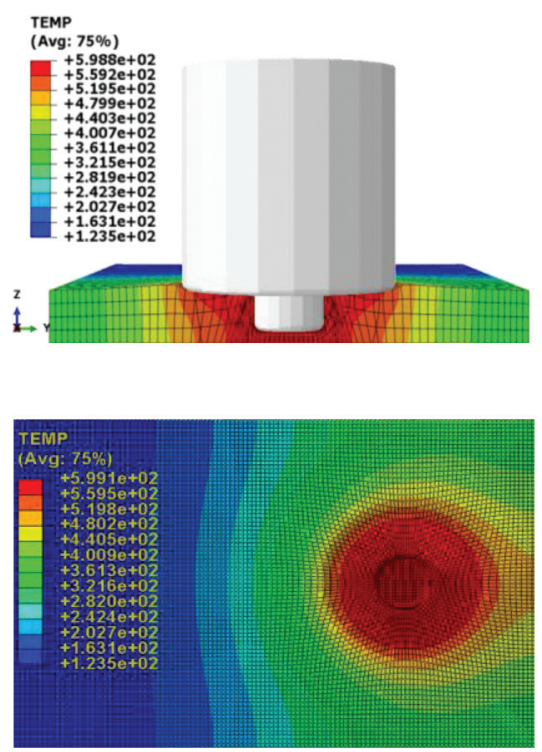

(c)
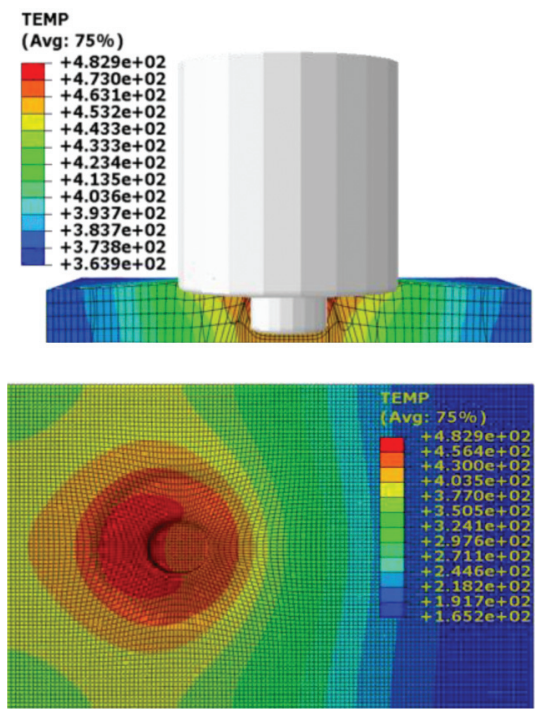

(f)

FiguRE 4: Transient temperature distributions on the surface and through-thickness in the workpiece at times (a) $0.9 \mathrm{sec}$, (b) $6.05 \mathrm{sec}$, (c) $12.1 \mathrm{sec}$, (d) $12.3 \mathrm{sec}$, (e) $19.8 \mathrm{sec}$ (mid-length), and (f) $27.5 \mathrm{sec}$ (end of weld).

4.2. Mechanical Response Evolution. The ALE model proposed within this paper has the capability of predicting stresses emanated during three phases of FSW of AA 7075T651 plates. Figure 7 displays the von Mises stress contours at six distinct time points starting from the beginning of the process and up to the end. At the first commencement of contact between the tool and AA 7075 plate, an elevated compressive stress of $471 \mathrm{MPa}$ was created directly in the region underneath the tool pin and neighbour area; this high value of stress is a normal result for the axial force subjected at the start of the plunging stage as shown in Figure 7(a). As the tool goes deeper during the plunging stage, the heat generated at the interface region between the tool and AA 7075 workpiece increases too causing a status of local metal softening which in turn leads the stress within the stirring region to be reduced highly as shown in Figure 7(b). It can be seen that at $6.05 \mathrm{sec}$ the area of maximum stress jumped to some location away from the pin-workpiece interface region but still there was a high-stress region with cylindrical boundaries around the tool pin as indicated by the von Mises stress contour. However, when complete contact between tool shoulder and AA 7075 plate occurs, an excessive amount of heat will generate, and this makes the cylindrical high-stress contours slide away progressively from the region of complete contact. At time $12.1 \mathrm{sec}$ the high rise of temperature in the zone beneath the tool leads to material softening which in turn makes it so easy to be stirred; also the stress magnitude decreased further approaching zero $(<79 \mathrm{MPa})$ as shown in Figure $7(\mathrm{c})$. During the dwell time, the stress value in the area underneath the tool pin increased 


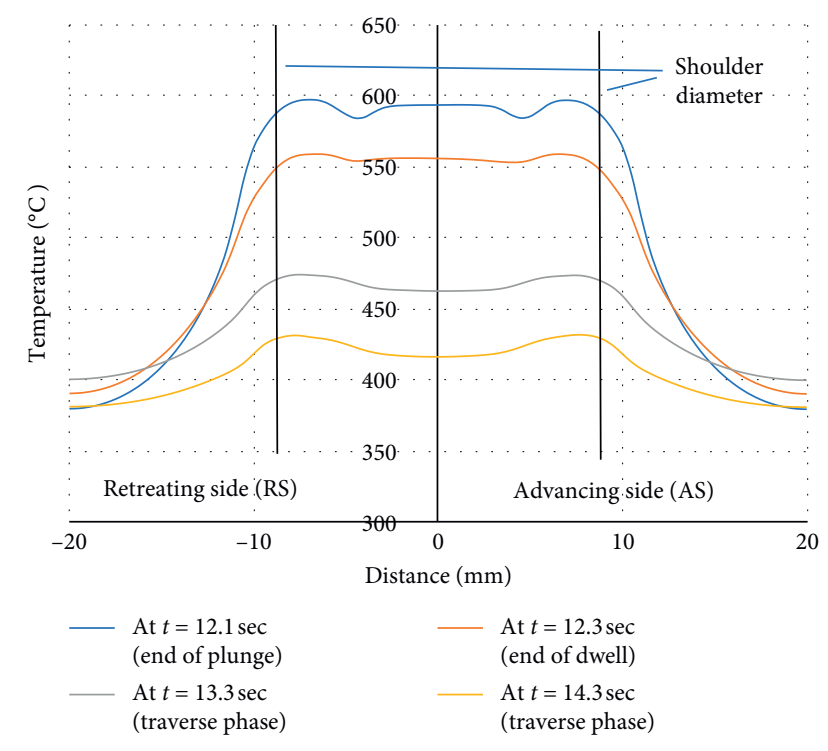

Figure 5: Temperature profile across plate width.

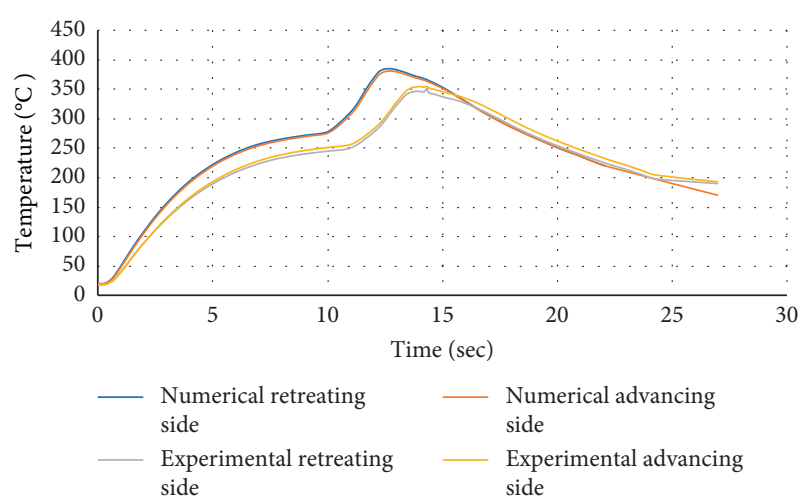

FIgURE 6: Temperature history of two points located on advancing and retreating sides of the welded specimen.

at a steady proportion reaching almost a value of $102 \mathrm{MPa}$ in the circumferential region while it remained less than $64 \mathrm{MPa}$ in the remote area as indicated in Figure 7(d). From $12.3 \mathrm{sec}$ and ahead, the stress inside the stirring zone reached a steady-state value and no important modifications in the stress magnitude were observed as shown in Figures 7(e) and $7(\mathrm{f})$. The variation of the stress value throughout the entire process time indicates that workpiece temperature performs a significant function in controlling the stress magnitude and consequently in the building of a flawless weld.

As can be seen from Figure 7(f) the stress out of the stirring zone or region that is away from the zone of toolworkpiece interaction increased from zero to a value within the range of 71-460 $\mathrm{MPa}$. The dimensional limitation used in this simulation (60 $\mathrm{mm}$ in length and $40 \mathrm{~mm}$ in width) was the reason behind this stress value. On behalf of this, if the plate temperature is reduced down to the room temperature, a subsequent internal stress profile may be generated through the path of welding.

It is well known that the microstructural map of the resulting welding joint is highly affected by both temperature profile and plastic deformation that take place during FSW process; on this account, the current study extends its features to include the study of the plastic strain quantity. The variation of the equivalent plastic strain along a path passing through the plunging position across the specimen width (Section A-A) is shown in Figure 8. The figure shows symmetrical plastic strain distribution about the joint line during tool penetration except when full contact between the tool shoulder and AA 7075 plate occurs in which the advancing side will preserve little higher average plastic strain than the retreating side. This result agrees well with the previous results published by Buffa et al. [27]. The highest plastic strain value is almost near the center of the welding line from the advance side.

\subsection{Tool Reaction Force and Heat Generation. Another} important feature that the current finite element model can predict is the tool reaction force throughout the entire time of the FSW process. As indicated in Figure 9 the tool pin is subjected to high reaction forces during the plunge stage. Due to these reaction forces, the tool pin experiences high compressive stresses, which in turn might result in the pin collapse, especially when the mechanical strength of the tool is not high enough to withstand externally subjected loads. The force analysis showed that the horizontal force components $x \& y$ were so small compared to the transverse $z$ direction component that can be neglected. As seen in Figure 9, the reaction force begins to increase immediately after the first onset of contact between the tool and AA 7075 workpiece and suddenly it jumps to its peak value when complete contact between tool shoulder and workpiece takes place. Later, the value of the force gets a gradual decrease with fluctuations during the welding stage. The unexpected decay in reaction force value after $12.1 \mathrm{sec}$ is due to local material temperature increase under the tool pin. Although the current model shows good trend correlation in force measurement with the previous experimental published studies by Liu et al. [28] and Lambiase et al. [29], it is necessary to mention that it returns a little high overestimated force value when compared to the experimentally measured one. The reason behind this difference is as follows: first, the tool was considered as a rigid body which means that high reaction forces are going to be generated since no mechanical (elastic or plastic) deformations are taking place. The second reason is that the inertia force is expected to be higher due to the simulation time speed-up.

The heat generated due to both friction and plastic deformation was computed through the three simulation steps as illustrated in Figure 10. The figure also shows that both types of energies are increasing in a proportional way to the time until complete contact between tool and AA 7075 workpiece takes place; thenceforth a sudden mutation in energy magnitude is noticed. The generation rates for both energies get greater after the transition area as shown in Figure 10. As can be seen, the frictional energy is much higher than the plastic energy; this agrees with the conclusion driven in former literature that states that the friction oversees supplying most of the heat needed throughout the 


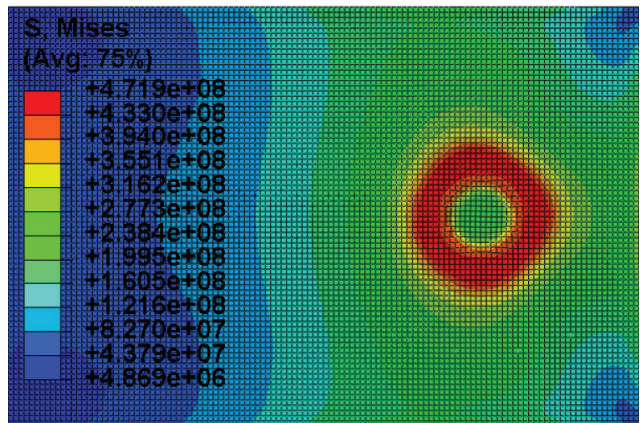

(a)

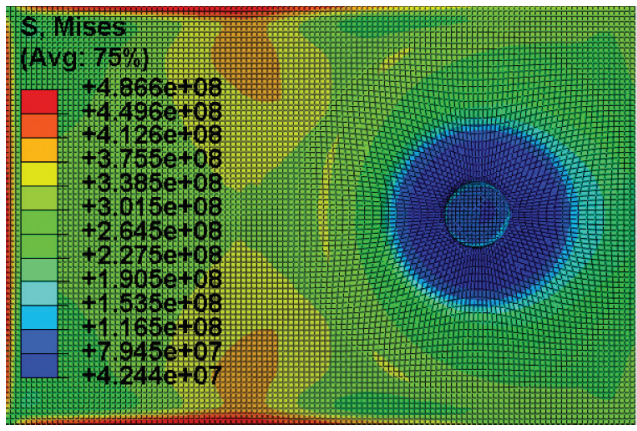

(c)

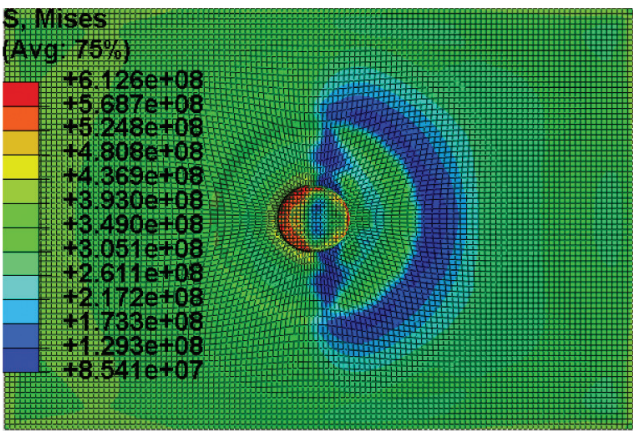

(e)

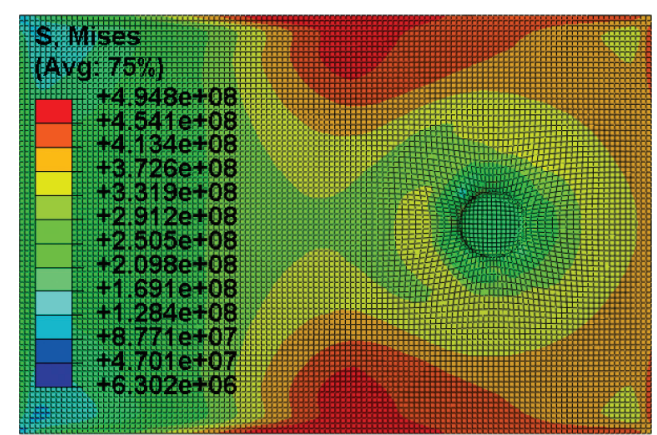

(b)

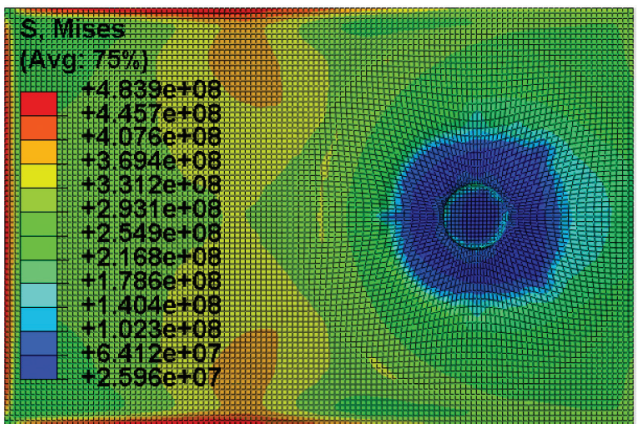

(d)

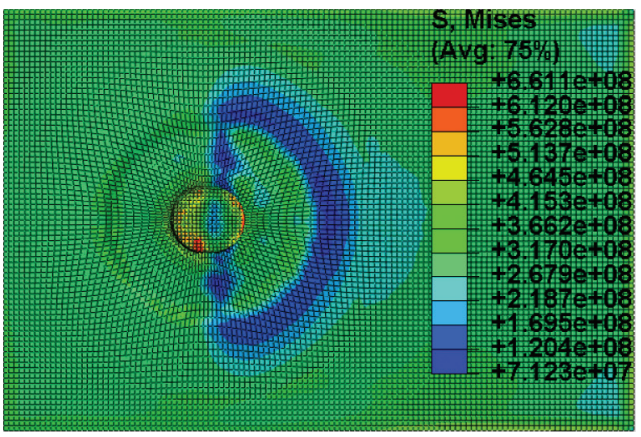

(f)

Figure 7: Von Mises stress contours at six distinct time points of FSW process: (a) $0.9 \mathrm{sec}$, (b) $6.05 \mathrm{sec}$, (c) $12.1 \mathrm{sec}$, (d) $12.3 \mathrm{sec}$, (e) $19.8 \mathrm{sec}$, and (f) $27.5 \mathrm{sec}$.

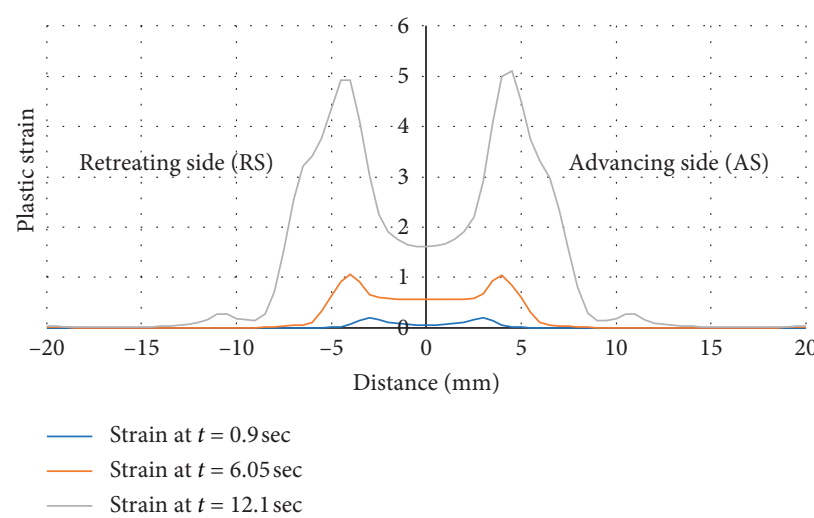

(a)

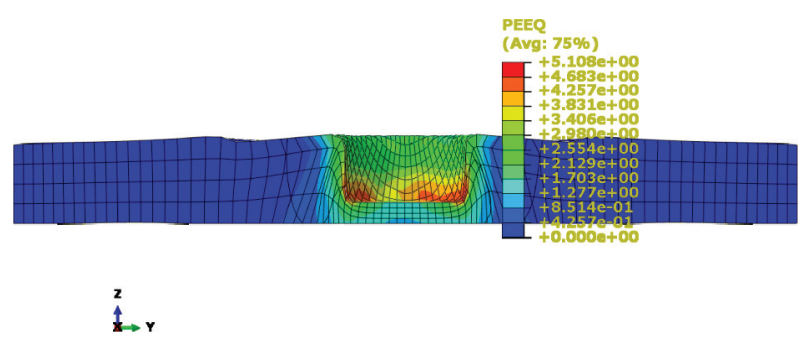

(b)

Figure 8: (a). Plastic strain distribution across plate width (b). Transverse cross section showing the maximum plastic strain. 


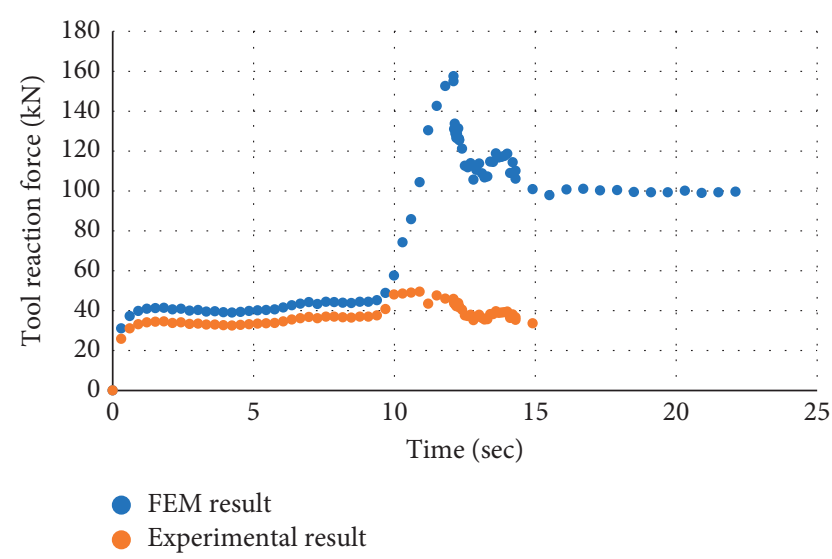

FIgURE 9: Tool reaction force versus time throughout the entire FSW process.

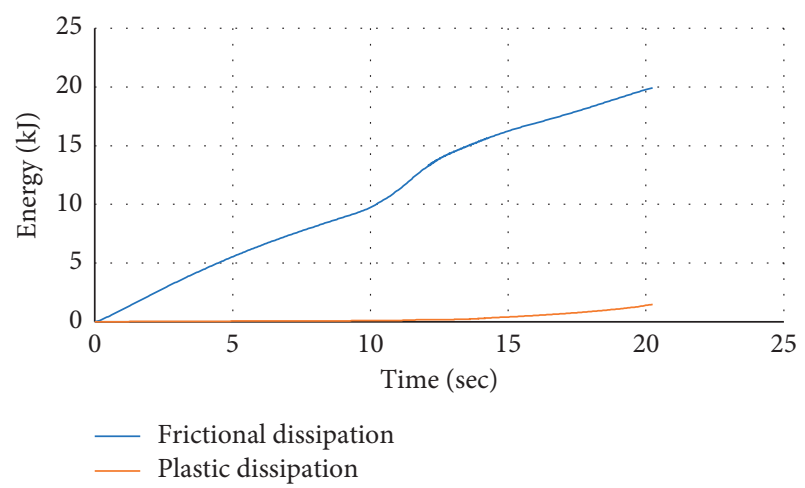

Figure 10: Energy dissipation versus time.

simulation, approximately (92\%) even when severe conditions like complete contact and intense plastic strain had occurred. This fact also supports the conclusion that the sliding condition was predominant during the contact modeling .

\section{Conclusions}

The current study implements a three-dimensional explicit finite element analysis to evaluate temperature and stresses' fields generated during FSW of AA 7075-T651 plates. The model simulated plunging, dwelling, and traverse stages involved during the FSW process. The study showed that while the tool is penetrating the AA 7075 workpiece, a high-temperature gradient began at the region underneath the tool pin and then translated to the corner edge formed by the shoulder and workpiece. A peak temperature of $599^{\circ} \mathrm{C}$ which is lower than the melting point of the AA 7075-T651 alloy was noticed as a signalizing event of solidstate welding. The temperature was symmetrically distributed across the plate width and the advancing side (AS) showed a higher plastic strain value than the retreating side (RS). The temperature field generated due to the frictional heat at the contact region was used to preheat the workpiece in the dwelling stage and later the heat gradually was stabilized during the transverse stage to develop a quasi-steady temperature field around the tool pin. The study also has the ability of burring figuration when full contact comes into existence.

\section{Data Availability}

The data used to support the findings of this study are available from the corresponding author upon request.

\section{Conflicts of Interest}

No potential conflicts of interest were declared by the authors.

\section{References}

[1] R. S. Mishra and M. Komarasamy, Friction Stir Welding of High Strength 7XXX Aluminum Alloys, Elsevier, Denton, TX, USA, 2016.

[2] J. Zhang, P. Upadhyay, Y. Hovanski, and D. P. Field, "Highspeed friction stir welding of AA7075-T6 sheet: microstructure, mechanical properties, micro-texture, and thermal history," Metallurgical and Materials Transactions A, vol. 49, no. 1, pp. 210-222, 2018.

[3] A. A. Chegeni and P. Kapranos, "A microstructural evaluation of friction stir welded 7075 aluminum rolled plate heat treated to the semi-solid state," Metals, vol. 8, no. 1, p. 41, 2018.

[4] P. H. Shah and V. Badheka, "An experimental investigation of temperature distribution and joint properties of Al 7075 T651 friction stir welded aluminium alloys," Procedia Technology, vol. 23, pp. 543-550, 2016.

[5] M. K. Abbass, M. M. Al-kubaisy, and R. Abdulkadhim, "Optimization of friction stir welding process parameters of dissimilar AA2024-T3 T3 and AA7075-T73 aluminum alloys by using taguchi method," Al-Khwarizmi Engineering Journal, vol. 12, pp. 100-109, 2016.

[6] S. K. Hussein, "Analysis of the temperature distribution in friction stir welding of AA 2024-T3 and AA 6061-T6 using finite element method," UPB Scientific Bulletin, vol. 78, no. 4, pp. 119-132, 2016.

[7] S. K. Hussein, "Theoretical analysis, finite element method and optimization of heat generation in friction stir welding from different probe and shoulder profiles," International Journal of Advance Research, vol. 4, no. 5, pp. 37-46, 2016.

[8] V. Soundararajan, S. Zekovic, and R. Kovacevic, "Thermomechanical model with adaptive boundary conditions for friction stir welding of $\mathrm{Al}$ 6061," International Journal of Machine Tools and Manufacture, vol. 45, no. 14, pp. 15771587, 2005.

[9] M. Esmaily and A. Shokuhfar, "Numerical simulation of heat transfer in friction stir welding of 7075-T6 aluminum alloy and high carbon steel using Arbitrary Lagrangian Eulerian technique," Materialwissenschaft und Werkstofftechnik, vol. 41 , no. 5, pp. 350-355, 2010.

[10] K. N. Salloomi and S. Al-Sumaidae, "Numerical validation of temperature distribution in friction stir welded aluminum 7075-T651 plates using pseudo heat transfer model," Annales de chimie Science des Matériaux, vol. 41, no. 1-2, pp. 29-38, 2017.

[11] R. Jain, S. K. Pal, and S. B. Singh, "A study on the variation of forces and temperature in a friction stir welding process: a finite element approach," Journal of Manufacturing Processes, vol. 23, pp. 278-286, 2016. 
[12] M. Riahi and H. Nazari, "Analysis of transient temperature and residual thermal stresses in friction stir welding of aluminum alloy 6061-T6 via numerical simulation," The International Journal of Advanced Manufacturing Technology, vol. 55, no. 1-4, pp. 143-152, 2011.

[13] M. M. El-Sayed, A. Y. Shash, and M. Abd-Rabou, "Finite element modeling of aluminum alloy AA5083-O friction stir welding process," Journal of Materials Processing Technology, vol. 252, pp. 13-24, 2018.

[14] F. Al-Badour, N. Merah, A. Shuaib, and A. Bazoune, "Coupled Eulerian Lagrangian finite element modeling of friction stir welding processes," Journal of Materials Processing Technology, vol. 213, no. 8, pp. 1433-1439, 2013.

[15] M. Hossfeld, "A fully coupled thermo-mechanical model of friction stir welding," in Proceedings of the 11th International Symposium on Friction Stir Welding, Cambridge, UK, May 2016.

[16] B. Meyghani, M. Awang, S. Emamian, and N. M. Khalid, "Developing a finite element model for thermal analysis of friction stir welding by calculating temperature dependent friction coefficient," in Proceedings of the 2nd International Conference on Mechanical, Manufacturing and Process Plant Engineering, Kuala Lumpur, Malaysia, April 2017.

[17] H. Luo, L. Xiao, J. Wu, H. Zhang, and W. Zhou, "Structure design and thermal analysis of a new type of friction stir weld spindle," Advances in Mechanical Engineering, vol. 9, no. 5, 2017.

[18] ABAQUS, Inc., ABAQUS/Explicit, ABAQUS, Inc., Providence, RI, USA, 2006.

[19] A. J. M. Spencer, Continuum Mechanics, Longman Press, London, UK, 2004.

[20] H. Li, D. Mackenzie, and R. Hamilton, "Multi-Physics simulation of friction stir welding process," Engineering Computations, vol. 27, no. 8, pp. 967-985, 2010.

[21] P. Colegrove, "3-dimensional flow and thermal modeling of the friction stir welding process," in Proceedings of the 2nd International Symposium on Friction Stir Welding, Gothenburg, Sweden, June 2000.

[22] K. C. Jørgensen and V. Swan, "Modeling of armour-piercing Projectile Perforation of thick aluminium plates," in Proceedings of the 13th International LS-DYNA Conference, Detroit, MI, USA, June 2014.

[23] K. C. Mills, Recommended Values of Thermophysical Properties for Selected Commercial Alloys, National Physical Laboratory and ASM International, Woodhead Publishing Limited, Cambridge, UK, 2002.

[24] K. N. Salloomi, "Fully coupled thermomechanical simulation of friction stir welding of aluminum 6061-T6 alloy T-joint," Journal of Manufacturing Processes, vol. 45, pp. 746-754, 2019.

[25] K. Fraser, L. Kiss, L. St-Georges, and D. Drolet, "Optimization of friction stir weld joint quality using a meshfree fullycoupled thermo-mechanics approach," Metals, vol. 8, no. 2, p. 101, 2018.

[26] G. S. Reese, Analytical Thermal Model of Friction Stir Welding with Spatially Distributed Heat Source, BYU Scholar Archive, Brigham, UT, USA, 2012.

[27] G. Buffa, J. Hua, R. Shivpuri, and L. Fratini, “"'A Continuum based Fem model for friction stir welding - model Development," Materials Science and Engineering: A, vol. 419, no. 12, pp. 389-396, 2006.

[28] X. Liu, S. Lan, and J. Ni, "Thermal mechanical modeling of the plunge stage during friction-stir welding of dissimilar Al 6061 to TRIP 780 steel," Journal of Manufacturing Science and Engineering, vol. 137, no. 5, Article ID 051017, 2015.
[29] F. Lambiase, A. Paoletti, and A. Di Ilio, "Forces and temperature variation during friction stir welding of aluminum alloy AA6082-T6," The International Journal of Advanced Manufacturing Technology, vol. 99, no. 1-4, pp. 337-346, 2018. 